\title{
Gravity Energy Storage with Suspended Weights for Abandoned Mine Shafts
}

\author{
Thomas Morstyn ${ }^{\mathrm{a}, *}$, Martin Chilcott ${ }^{\mathrm{b}}$, Malcolm D. McCulloch ${ }^{\mathrm{a}}$ \\ ${ }^{a}$ Department of Engineering Science, University of Oxford, Parks Road, Oxford OX1 3PJ \\ ${ }^{b} 2$ degrees, 228-240 Banbury Road, Oxford, OX2 7BY, United Kingdom
}

\begin{abstract}
This paper investigates the potential of using gravity energy storage with suspended weights as a new technology for redeveloping abandoned deep mine shafts. The technology has relatively low energy density, but has advantages including a power capacity decoupled from its energy capacity, no cycle-limit and the potential to be combined with compressed air energy storage. It is currently being trialled in the United Kingdom, targeting abandoned coal mines. The paper presents analysis for sizing the suspended weight to maximize the energy storage capacity, given a mine shaft's physical dimensions. In addition, it is shown that the power capacity of the system's motor and power electronics determine the maximum ramp-rate, and therefore the range of power system services that can be provided. A case study is presented, estimating the total energy storage capacity which could be obtained by converting abandoned mines in the United Kingdom Midlands, using geographic information system data from the United Kingdom Government Coal Authority Abandoned Mine Catalogue.
\end{abstract}

Keywords: Energy storage, gravity, GIS, mine, power system, suspended weight

\section{Introduction}

Energy storage systems are becoming an increasingly important power system component due to the integration of variable renewable generation sources [1]. This is expected to continue as the costs of solar and wind generation decrease further, and countries aim to achieve more stringent emission reduction targets on the path towards decarbonization [2].

Energy storage systems primarily offer value to power systems by absorbing power during periods with low demand and injecting power during periods with high demand. This activity is divided into different services, which depend on the timescale and network-location where energy is provided [3]. For example, frequency regulation services involve injecting or absorbing power to balance aggregate supply and demand at fast time-scales. In the United Kingdom (UK), National Grid distinguishes between frequency regulation provided within $1 \mathrm{sec}-$ ond, 10 seconds and 30 seconds [4].

Wholesale energy trading can be done with a lower ramprate, since it involves longer (e.g. 30 minute) trading intervals. Storage systems can perform energy arbitrage by selling energy when wholesale energy prices are high, and buying energy when prices are low [5]. Energy storage systems in distribution networks can also offer localized services, such as voltage regulation and peak-shaving [6].

A range of energy storage technologies exist, each with different trade-offs for particular applications. However, pumped hydropower is still the dominant form of installed power system energy storage worldwide [7]. Although the cost of lithium-ion

\footnotetext{
${ }^{*}$ Corresponding author

Email address: thomas.morstyn@eng.ox.ac.uk (Thomas Morstyn)
}

batteries has decreased significantly in recent years, their levelized cost of energy remains higher than the levelized cost of energy of pumped hydropower and other gravity energy storage technologies [8]. Also, gravity energy storage technologies, including pumped hydropower, have two key advantages over electrochemical batteries (e.g. lithium-ion, lead-acid); (i) their capacity does not degrade each cycle and (ii) their power capacity is decoupled from their energy capacity.

Using a battery energy storage system for energy arbitrage is only profitable if the price-gap between high and low priced periods is greater than the degradation cost associated with cycling the battery [9]. In addition, the power capacity of a battery energy storage system is coupled to its energy capacity, since cycling the battery at a high $\mathrm{C}$-rate results in increased degradation [10]. This limits the opportunities for battery energy storage systems to take advantage of short periods with large price-gaps (e.g the average price-gap between the highest and lowest priced 30 minute-long intervals during the day will be greater than the average price-gap between the highest and lowest hour-long intervals). The key advantages of electrochemical battery energy storage technologies are their high power and energy densities, which makes them suited for applications for which space and weight are at a premium, including electric vehicles and uninterruptible power supplies [11].

Pumped hydropower is limited by the number of suitable locations, since it requires large areas of land for an upper and lower reservoir, which must be separated in height [12]. This has created interest in developing new forms of gravity energy storage, to capture the benefits of pumped hydropower without its land-use requirements [13]. A particular technology patented by the US company Gravity Power is based on a large underground piston, which is lifted hydraulically to store en- 
ergy, and then released to push water through a turbine [14]. The cost of this system is primarily made up of excavations (approximately 57\% of the total cost) and a reinforced concrete container to resist the load pressure (approximately $25 \%$ of the total cost) [8].

Another approach for underground energy storage is to make use of existing excavations. The UK Midlands region has thousands of deep shaft coal mines which went into disuse as their resources were exhausted and lower-cost coal industries developed in other countries. These mines can have shafts hundreds of meters in depth, and extensive tunnel networks, opening the possibility for a range of different energy storage technologies. The decline of the mining industry had a long term impact on employment in the Midlands [15], and the UK government considers it a priority area for economic renewal [16]. Economic renewal is also a policy objective for former mining regions in the United States [17] and Canada [18]. Redeveloping abandoned mines for energy storage offers a second life to an otherwise unused asset, and could help support local renewable energy projects. Where there is sufficient surrounding land for an upper reservoir, underground pumped hydropower may be attractive [19], but other technologies have also been proposed including heat [20] and compressed air energy storage [21]. Successful redevelopment of an abandoned mine will likely rely on an energy storage technology (or combination of technologies) suited to the particular site.

A new gravity energy storage technology using suspended weights has been proposed by the UK company Gravitricity. Innovate UK has funded a $£ 650,000$ trial of the system. This system offers several advantages, including minimal surface landuse and the possibility of combining it with compressed air energy storage [22]. The technology is expected to be most desirable for existing deep mine shafts, but the maximum energy storage capacity is limited by the dimensions of the shaft and the maximum weight which can be practically used. This motivates an investigation of the potential opportunity for energy storage that this type of system represents for former mining regions.

This paper presents the first analysis of the technical potential of using gravity energy storage with suspended weights as a new technology for redeveloping abandoned deep mine shafts. Analysis is presented for sizing the suspended weight to maximize the energy storage capacity, given a mine shaft's physical dimensions. It is also shown that the power capacity of the system's motor and power electronics determine the maximum ramp-rate, and therefore the range of power system services that can be provided. A case study is presented, estimating the total potential energy storage capacity for the UK Midlands as a major former coal mining region. This analysis makes use of geographic information system (GIS) data from the UK Government Coal Authority Abandoned Mine Catalogue, with location, depth and diameter information for 3,243 abandoned mines with vertical shafts.

Rather than considering operation for a particular application and energy storage usage profile, the paper focuses on three important technical characteristics for energy storage systems: (i) energy storage capacity, (ii) power capacity and (iii) ramp-

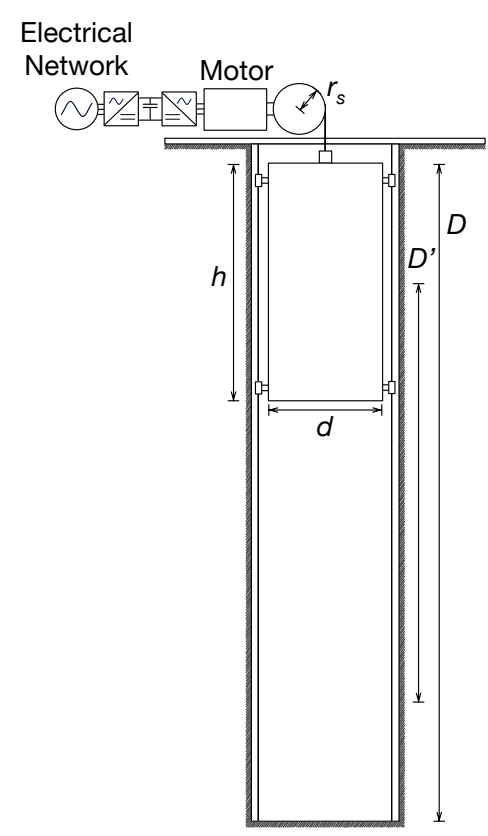

Figure 1: A schematic diagram of the suspended weight gravity energy storage system. $h$ is the height of the suspended weight, $d$ is the diameter, $D$ is the depth of the shaft, $D^{\prime}=D-h$ is the usable depth for energy storage and $r_{s}$ is the traction sheave radius. Additional details of the connections and guidance system are provided in the patent filed by Gravitricity [22].

rate. These characteristics are often used to compare different energy storage technologies [23]. In addition, they can be used as inputs for technology independent energy storage scheduling algorithms, for applications including peak shaving [24] and frequency response [25].

The paper focuses on the technical features of the technology and the potential energy storage capacity it could provide, rather than its economics. Storage Lab has reported results from a commercial study completed for Gravitricity, showing the system could be competitive in terms of levelized cost of storage for grid frequency response applications compared with lithium-ion batteries, lead-acid batteries and flywheels [26]. Currently, the full report is not publicly available.

The rest of the paper is organized as follows. Section 2 describes the system's design and principle of operation. Section 3 analyses the size of the suspended weight, and the associated power electronics, motor and wire ropes. A case study investigating the potential energy storage capacity from deep shaft coal mines in the UK Midlands is presented in Section 4. Section 5 concludes the paper.

\section{Suspended Weight Energy Storage}

Fig. 1 shows a schematic digram of the suspended weight gravity energy storage system. The main components of the system are (i) the mine shaft, (ii) the suspended weight, (iii) an induction motor connected to the weight by wire ropes and (iv) an active front end inverter providing a bidirectional interface between the motor and the electrical network. Note that to reduce the size of the motor and inverter, several motor-inverter 
pairs could be used in parallel.

The system's design is similar to modern cranes with regenerative braking [27]. Energy is stored by drawing power from the electrical network to lift the suspended weight. The power drawn from the network is related to the speed and mass of the weight. Additional power is required to achieve higher rates of acceleration, which means that higher capacity motors and power electronics are required to provide power system services with higher ramp-rates (for example 1 second frequency response).

Power is injected into the grid by releasing the mass and recovering energy with regenerative braking. This requires an active front end inverter [28]. The AC mains are connected to a bidirectional active front end rectifier. A DC link capacitor provides an interface between the rectifier and a voltage source inverter, which supplies the motor. Pulse width modulation (PWM) control of the inverter is used to regulate the motor torque and speed. The bidirectional rectifier is controlled to maintain the DC-link voltage and to set the energy storage system's power factor, which is equivalent to controlling the system's real and reactive power flows.

There is not direct connection between the suspended weight and the sides of the shaft, but the suspended weight does require an above ground support structure. Structural and geotechnical design will be required to ensure it can support the weight, without placing excessive stresses on the mine shaft walls. One approach for this would be to conduct a finite element analysis, to model the stresses on the mine shaft, considering data including three dimensional mine maps and rock properties [29].

\section{System Sizing}

This section analyses the size of the suspended weight to maximize the energy storage capacity of the system, the required power capacity of the motor and power electronics to achieve a desired ramp-rate and the wire ropes required for the suspended weight.

\subsection{Suspended Weight}

It is assumed that the system uses a cylindrical weight. The energy storage capacity of the system is given by,

$$
E=\eta m g D^{\prime}
$$

where $\eta$ is the round-trip efficiency, $m$ is the mass of the suspended weight, $g$ is the acceleration due to gravity and $D^{\prime}$ is the usable depth of the shaft for storing energy.

Let $h$ be the height of the cylindrical weight and let $d$ be its diameter. Then, the volume is given by,

$$
V=\frac{\pi d^{2} h}{4}
$$

For a weight made of a material with density $\rho$, the mass of the weight is given by $m=\rho V$. For a shaft with depth $D$, the usable depth of the shaft for lifting the weight is given by,

$$
D^{\prime}=D-h=D-\frac{4 m}{\pi d^{2} \rho} \text {. }
$$

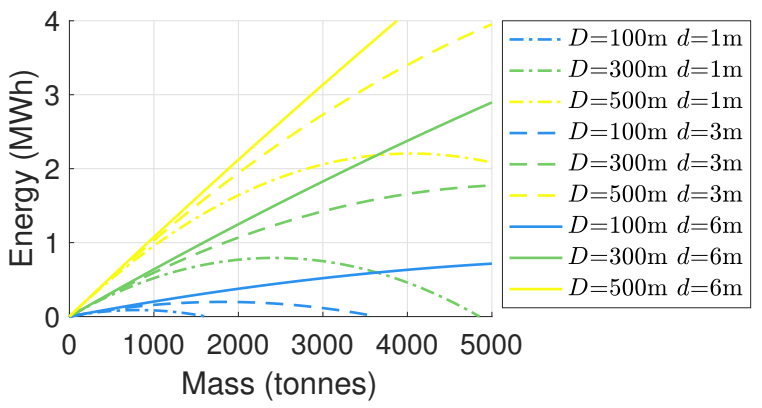

Figure 2: The energy storage capacity for suspended weights with different masses, in mine shafts with different depths $D$ and diameters $d$, with round-trip efficiency $\eta=80 \%$.

Therefore, the total energy storage capacity is given by,

$$
E=\eta\left(m g D-\frac{4 m^{2} g}{\pi d^{2} \rho}\right) .
$$

Increasing the height of the cylindrical weight increases the mass, but reduces the usable shaft depth, creating a trade-off for the energy capacity. This is captured by the derivative of the energy capacity with respect to mass,

$$
\frac{d E}{d m}=\eta\left(g D-\frac{8 m g}{\pi d^{2} \rho}\right) .
$$

Also, the suspended weight may have some maximum practical mass $\bar{m}$ which can be accommodated by the ropes and support structure. Given this constraint, the mass that maximizes the energy storage capacity is given by,

$$
m^{*}=\min \left\{\bar{m}, \frac{D \pi \rho d^{2}}{8}\right\} .
$$

This is equivalent to sizing the cylindrical suspended weight to have height,

$$
h^{*}=\frac{4 m^{*}}{\pi d^{2} \rho} .
$$

Fig. 2 shows how the energy storage capacity varies with the mass of the suspended weight, for mine shafts with different depths and diameters. As shown, the maximum energy storage capacity of mine shafts with small diameters is limited, since increasing the mass requires a relatively larger increase in the height of the cylindrical weight, resulting in a reduction in the usable shaft depth. The efficiency will depend on the power electronics, motor and operating power, but will not directly depend on the physical dimensions of the suspended weight. For a particular system, the efficiency is expected to be relatively constant when operating above $20 \%$ of the rated power [30]. For Fig. 2, the round-trip efficiency has been assumed to be $80 \%$. This value has been proposed by Gravitricity [22], and has been used when assessing similar systems, including cranes with regenerative braking [27] and Gravity Power's storage technology [8]. 


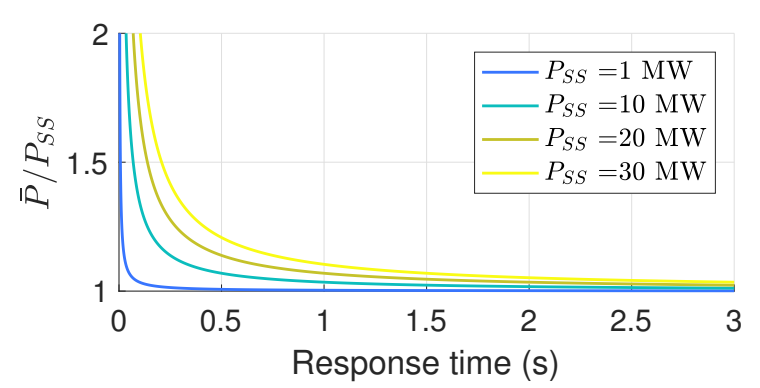

Figure 3: The ratio between the short-time power rating $\bar{P}$ and steady-state power rating $P_{S S}$ for a 3,000 tonne gravity energy storage system, given different power ratings and response times.

\subsection{Motor and Power Electronics}

The force required to lift the weight is given by,

$$
F=m g+m a,
$$

where $a=d v / d t$ is the acceleration of the weight. The differential equation of motion for the drive is given by,

$$
T=F r_{s}+J \frac{d \omega}{d t}=m g r_{s}+m a r_{s}+\frac{J}{r_{s}} a,
$$

where $T$ is the motor torque, $\omega=v / r_{s}$ is the angular velocity, $J$ is the rotational inertia and $r_{s}$ is the traction sheave radius. The machine output power is obtained by multiplying (9) by $\omega$,

$$
P=m v g+\left(m+\frac{J}{r_{s}^{2}}\right) v a .
$$
by,

The steady-state power to maintain a constant speed is given

$$
P_{S S}=m v g \text {. }
$$

Additional power is required to accelerate the weight to full speed. To provide fast time-scale power system services (e.g. fast frequency response) the energy storage system must be able to deliver power within a given response time. Assuming constant acceleration, achieving full speed $v$ from rest within a required response time $\tau$ requires,

$$
a=\frac{v}{\tau}=\frac{P_{s s}}{m g \tau} .
$$

Therefore, the maximum short-time power rating $\bar{P}$ is given by,

$$
\bar{P}=P_{S S}+\left(\frac{1}{m g^{2} \tau}+\frac{J}{r_{s}^{2} m^{2} g^{2} \tau}\right) P_{S S}^{2} .
$$

Given the mass of the weight is on the order of 1000 tonnes, while the rotational inertia for a medium voltage motor is on the order of $100 \mathrm{kgm}^{2}$ [31], the approximation $m \gg J / r_{s}^{2}$ can be used. Therefore, the required ratio of the short-time power rating to the steady-state power rating to achieve a desired response time of $\tau$ is given by,

$$
\frac{\bar{P}}{P_{S S}} \approx 1+\frac{P_{S S}}{m g^{2} \tau} .
$$
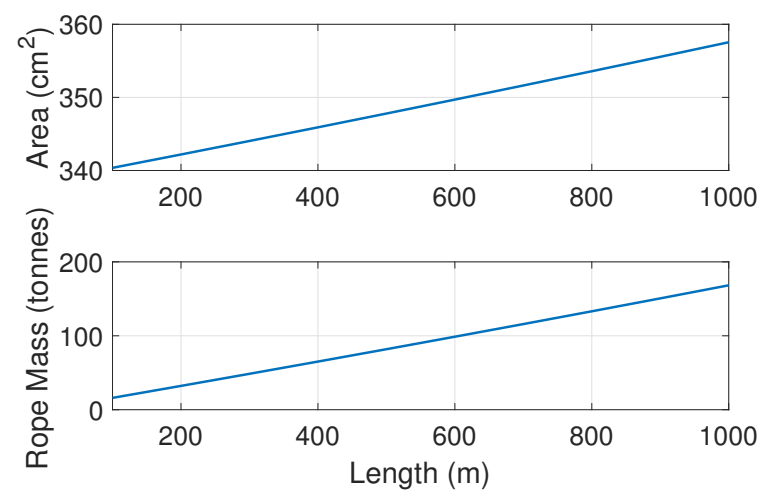

Figure 4: The total cross-sectional area and mass for steel wire ropes with tensile strength $896 \mathrm{MPa}$ and density $4,706 \mathrm{~kg} / \mathrm{m}^{3}$, for different rope lengths, assuming a 3,000 tonne suspended weight and a maximum acceleration of 0.3 $\mathrm{m} / \mathrm{s}^{2}$.

The motor and power electronics of the gravity energy storage system need to be designed with a stead-state power rating of $P_{S S}$ and a higher short-time power rating of $\bar{P}$. Fig. 3 shows how the short-time power rating varies as a function of the steady-state power rating and the required response speed for a 3,000 tonne system. As shown, the short-time power rating increases nonlinearly as the required response time becomes shorter. This effect is more pronounced for systems with higher power ratings.

\subsection{Wire Ropes}

The analysis in Sections 3.1 and 3.2 was simplified by neglecting the wire ropes. The wire ropes need to be designed to support the suspended mass and their own weight.

For a particular wire rope configuration, the tensile strength $\bar{\sigma}_{r}$ and the density $\rho_{r}$ can be obtained from the datasheet. A suspended weight with mass $m$ requires ropes with total crosssectional area $A_{r}$ and mass $m_{r}$ given by,

$$
\begin{aligned}
A_{r} & =\frac{m(g+\bar{a})}{\bar{\sigma}_{r}-l_{r} \rho_{r}(g+\bar{a})}, \\
m_{r} & =A_{r} l_{r} \rho_{r}
\end{aligned}
$$

where $\bar{a}$ is the maximum acceleration of the mass and $l_{r}$ is the rope length, which is equal to the usable shaft depth $D^{\prime}$. Fig. 4 shows the total cross-sectional area and mass for steel wire ropes with tensile strength $896 \mathrm{MPa}$ and density $4,706 \mathrm{~kg} / \mathrm{m}^{3}$ [32], for different rope lengths, assuming a 3,000 tonne suspended weight and a maximum acceleration of $0.3 \mathrm{~m} / \mathrm{s}^{2}$.

Note that the maximum possible depth of suspended weight gravity energy storage systems will be limited by the requirements that the wire ropes need to support their own weight, and the total cross-sectional area of the ropes must fit within the shaft. Other rope configurations and materials are also possible, including lighter weight composite ropes [33]. 


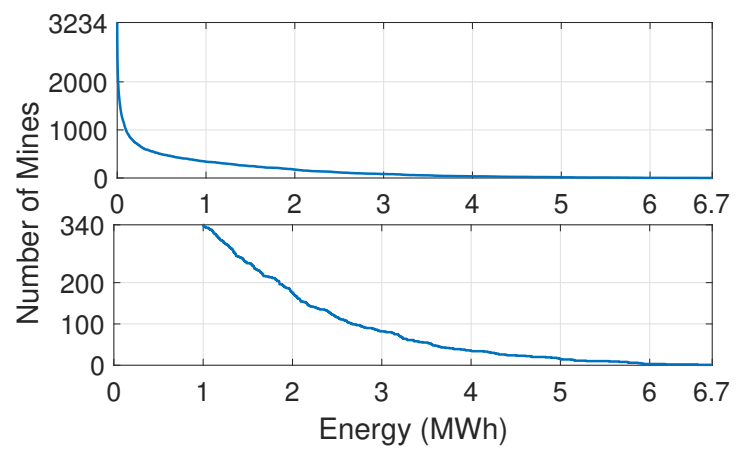

Figure 5: The number of mine shafts (for which depth and diameter information is available) with potential energy storage capacities above different levels. 340 mine shafts have a potential energy storage capacity above $1 \mathrm{MWh}$.

\section{Case Study: Abandoned Coal Mines in the United King- dom Midlands}

In this section, the total energy storage capacity which could be obtained by converting abandoned mines in the UK Midlands is estimated. This is done using GIS data on mine entries in the East and West Midlands European Parliament constituencies from the UK Government Coal Authority Abandoned Mine Catalogue. In general, a GIS dataset consists of a set of locations, and data linked to each location. GIS data is widely used for analyzing geographic information (e.g. in [34], GIS data is used to identify suitable locations for pumped hydropower).

The GIS dataset used in this study includes information on 42,126 abandoned mine entries in the Midlands. Of these, 38,370 are vertical shafts, while the remainder are horizontal adits. Depth and diameter information is available for 3,234 of the mine shafts, which are used for the analysis.

The analysis is based only on the data from the Coal Authority Abandoned Mine Catalogue. Surveys and feasibility studies would be necessary to verify the suitability of each mine, and the extent of works necessary to redevelop them for gravity energy storage. Also, there may also be are suitable shafts among the 35,136 which were excluded due to missing diameter and/or depth information, in which case the analysis may underestimate the total potential energy storage capacity.

The GIS dataset does not include geotechnical data, which would be necessary for detailed feasibility studies. In particular, it is assumed that a suitable support structure can be built at the site, and thus the maximum energy storage capacity estimated for the shafts could be overly optimistic. The analysis provides an initial estimate of the overall energy storage potential offered by the technology, which is important for considering whether further research and development is justified. In addition, particular sites which offer the highest potential energy storage capacity are identified, where it would make the most sense to prioritize detailed feasibility studies.

For each mine shaft, the suspended weight is sized using the analysis presented in Section 3.1 to maximize the energy storage capacity. Using the values Gravitricity has proposed for their system, a maximum mass of 3,000 tonnes has been assumed for the suspended weight. Note that the world's

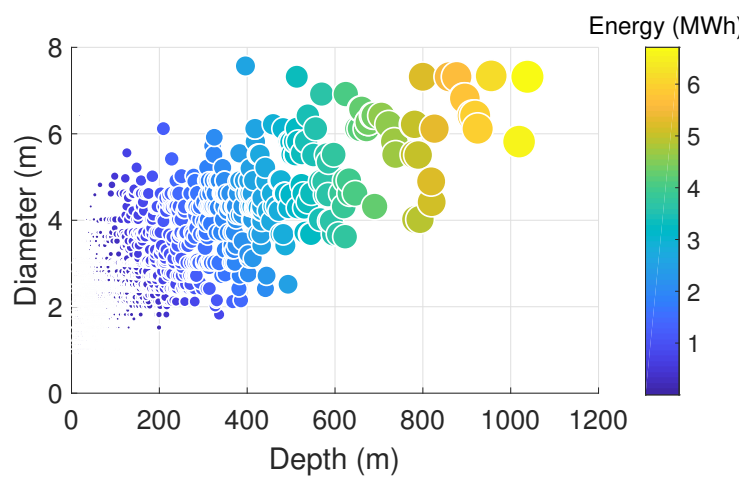

Figure 6: The diameter, depth and potential energy storage capacity for each of the 3,234 mine shafts (the shafts for which depth and diameter information is available). Each dot represents a mine shaft, with the potential energy capacity reflected by the color and area.

strongest crane can lift up to 20,000 tonnes [35], so this weight is not impractical. The round-trip efficiency for the gravity energy storage system is assumed to be $80 \%$. Iron ore has been selected for the cylinder material, based on its relatively high density $\left(5,150 \mathrm{~kg} / \mathrm{m}^{3}\right)$ to cost ratio compared with other options [36].

The total energy storage capacity of the 3,234 mines analyzed (the shafts for which depth and diameter information is available) is $1.07 \mathrm{GWh}$. Of these, 340 of the mines have maximum energy storage capacities over $1 \mathrm{MWh}$, and range up to 6.7 MWh. Considering only these mines accounts for 0.804 GWh of energy storage ( $74.7 \%$ of the total). Fig. 5 shows the number of mines with potential energy storage capacities above different levels, and Fig. 6 shows how the mine shafts vary in terms of diameter, depth and energy storage capacity. The maximum recorded depth for any of the shafts is $1,040 \mathrm{~m}$ and the maximum recorded diameter is $7.55 \mathrm{~m}$.

Fig. 7 is a heat map, showing how the potential energy storage capacity from converting abandonded mine shafts is distributed geographically throughout the Midlands. The mine shafts are spread across the region, offering the potential for them to be co-located with distributed renewable generation and to provide localized power system services.

The total potential energy storage capacity from using mine shafts in the UK Midlands is affected by the assumptions made for the maximum mass limit, and the density of the suspended weights. Fig. 8 shows the effect of varying the maximum mass assumption on the energy storage potential (using a density of $5,150 \mathrm{~kg} / \mathrm{m}^{3}$ ), and Fig. 9 shows the effect of varying the density assumption (using a maximum mass limit of 3,000 tonnes).

From Fig. 8, it can be seen that increasing the maximum mass limit has diminishing returns, since, as the limit is increased, shafts with relatively small diameters and heights will reach a mass for the suspended weight which maximizes their energy capacity. From a maximum mass limit of 1,000 tonnes to a limit of 10,000 tonnes, the total energy storage capacity increases from $0.48 \mathrm{GWh}$ to $2.27 \mathrm{GWh}$. The relative share of the energy capacity which is provided by mine shafts with energy capacities above $1 \mathrm{MWh}$ increases as the maximum mass increases, from $26.3 \%$ at 1,000 tonnes, up to $89.3 \%$ at 10,000 

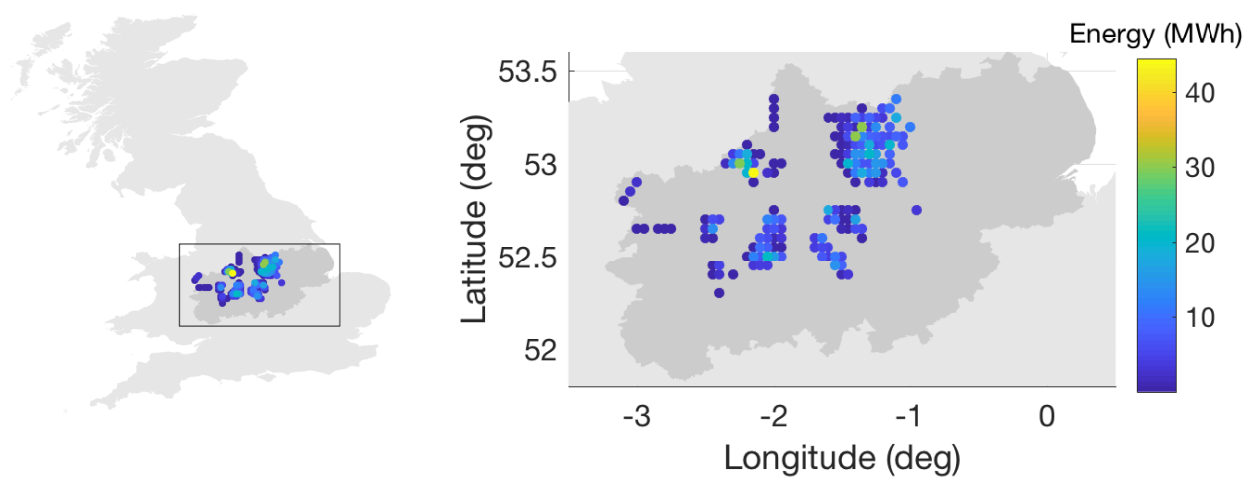

Figure 7: A heat map showing the potential energy capacity from abandoned mine shafts in the East and West Midlands European Parliament constituencies (indicated by the darkly shaded region).

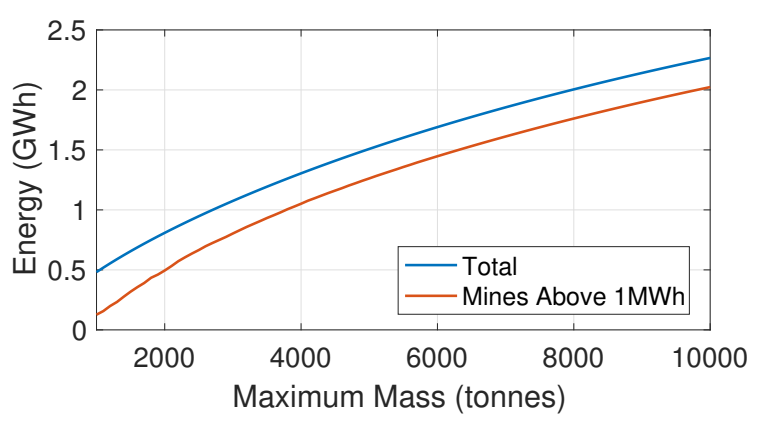

Figure 8: The effect of varying the maximum mass of the suspended weight on the energy storage potential of mine shafts in the UK Midlands (using a density of $\left.5,150 \mathrm{~kg} / \mathrm{m}^{3}\right)$.

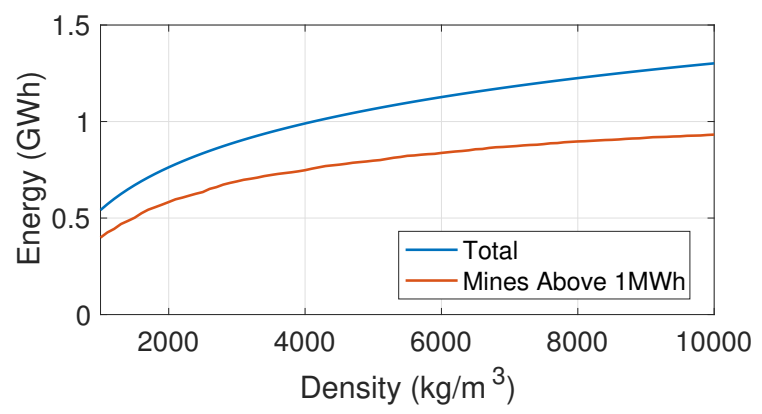

Figure 9: The effect of varying the density of the material used for the suspended weight on the energy storage potential of mine shafts in the UK Midlands (using a maximum mass limit of 3,000 tonnes).

tonnes. This is because it is mine shafts with relatively larger diameters and depths (and energy capacities) which see the largest energy capacity gains when the maximum mass constraint is relaxed.

From Fig. 9, it can be seen that increasing the density of the suspended weight also increases the potential energy storage capacity, again with diminishing returns. However, the relative share of the energy capacity which is provided by mine shafts with energy capacities above $1 \mathrm{MWh}$ actually decreases slightly, from $76.9 \%$ at $3,150 \mathrm{~kg} / \mathrm{m}^{3}$ (cement), to $73.1 \%$ at 8,050 $\mathrm{kg} / \mathrm{m}^{3}$ (steel). This is because it is mine shafts with relatively smaller diameters and depths (and energy capacities) which see the largest energy capacity gains when the density is increased.

\section{Conclusion}

This paper has investigated gravity energy storage using suspended weights as a new technology for redeveloping abandoned deep mine shafts. It has been shown how to size of the suspended weight to maximize the energy storage capacity for a mine shaft, given its physical dimensions. It has also been shown that faster ramp-rates increase the required short-time power rating of the system. This means that designers need to consider the range of power system services to be provided when sizing the motor and power electronics.

The United Kingdom Midlands has been used as a case study to investigate the potential energy storage capacity which the technology could offer a former coal mining region. Using data from the United Kingdom Government Coal Authority Abandoned Mine Catalogue, it has been estimated there are 340 mine shafts that could be converted into gravity storage units with energy capacities above $1 \mathrm{MWh}$, providing $0.804 \mathrm{GWh}$ of energy storage. This is based on the assumption that the suspended weights are limited to 3,000 tonnes and are constructed using iron ore. The sensitivity of the estimated energy storage capacity to these assumptions has also been analyzed.

Compared with other gravity energy storage technologies, using suspended weights requires minimal land-use and can make use of existing excavations. Another interesting opportunity is the potential to combine it with compressed air energy storage by sealing the underground shaft and adding a compressor and heat exchange. This could be used to create a hybrid energy storage system, with the compressed air energy storage providing bulk energy capacity, while gravity energy storage is used to increase the system's ramp-rate.

Surveys and feasibility studies will be required to obtain a more detailed understanding of the challenge involved in redeveloping abandoned mines, and to properly compare the cost of the technology with other energy storage options. The case for redeveloping particular mines could be further strengthened 
where there are opportunities to alleviate local distribution network congestion, or to store locally generated renewable energy to reduce imports/exports and to increase local asset utilization.

\section{Acknowledgments}

The authors would like to thank Zoe Abbate and the UK Government Coal Authority for making available the data from the Abandoned Mine Catalogue. This work was supported by the Oxford Martin Programme on Integrating Renewable Energy.

\section{References}

[1] X. Luo, J. Wang, M. Dooner, J. Clarke, Overview of current development in electrical energy storage technologies and the application potential in power system operation, Applied Energy 137 (2015) 511-536.

[2] W. F. Pickard, Massive Electricity Storage for a Developed Economy of Ten Billion People, IEEE Access 3 (2015) 1392-1407.

[3] A. Mohd, E. Ortjohann, A. Schmelter, N. Hamsic, D. Morton, Challenges in integrating distributed Energy storage systems into future smart grid, in: 2008 IEEE International Symposium on Industrial Electronics, 2008, pp. 1627-1632.

[4] National Grid, Balancing Services. URL nationalgrid.com/uk/electricity/balancing-services

[5] S. Vazquez, S. M. Lukic, E. Galvan, L. G. Franquelo, J. M. Carrasco, Energy Storage Systems for Transport and Grid Applications, IEEE Transactions on Industrial Electronics 57 (12) (2010) 3881-3895.

[6] T. Morstyn, B. Hredzak, V. G. Agelidis, Control Strategies for Microgrids with Distributed Energy Storage Systems: An Overview, IEEE Transactions on Smart Grid (2016) (Early Access).

[7] S. Rehman, L. M. Al-Hadhrami, M. M. Alam, Pumped hydro energy storage system: A technological review, Renewable and Sustainable Energy Reviews 44 (2015) 586-598.

[8] A. Berrada, K. Loudiyi, I. Zorkani, Sizing and economic analysis of gravity storage, Journal of Renewable and Sustainable Energy 8 (2) (2016) $1-15$.

[9] F. Wankmüller, P. R. Thimmapuram, K. G. Gallagher, A. Botterud, Impact of battery degradation on energy arbitrage revenue of grid-level energy storage, Journal of Energy Storage 10 (2017) 56-66.

[10] K. Smith, E. Wood, S. Santhanagopala, G. Kim, J. Neubauer, A. Pesaran, NREL: Models for Battery Reliability and Lifetime, Battery Congress (2013) 1-10.

[11] K. Divya, J. Østergaard, Battery energy storage technology for power systems - An overview, Electric Power Systems Research 79 (4) (2009) 511520 .

[12] M. Gimeno-Gutiérrez, R. Lacal-Arántegui, Assessment of the European potential for pumped hydropower energy storage : A GIS-based assessment of pumped hydropower storage potential, European Commission JCR Scientific and Policy Reports (2013) 1-74.

[13] M. Aneke, M. Wang, Energy storage technologies and real life applications - A state of the art review, Applied Energy 179 (2016) 350-377.

[14] A. Berrada, K. Loudiyi, I. Zorkani, Dynamic modeling and design considerations for gravity energy storage, Journal of Cleaner Production 159 (2017) 336-345.

[15] C. Beatty, S. Fothergill, R. S. Powell, Twenty years on: Has the economy of the UK coalfields recovered?, Environment and Planning A 39 (7) (2007) 1654-1675.

[16] HM Government, Midlands Engine Investment Portfolio.

URL gov.uk/government/publications/midlands-engine-investmentportfolio
[17] J. Skousen, C. E. Zipper, Post-mining policies and practices in the Eastern USA coal region, International Journal of Coal Science and Technology 1 (2) (2014) 135-151.

[18] L. Haiven, Regeneration among coal-mining communities in Canada and UK: The Role of Culture, Interrogating the New Economy: Restructuring Work in the 21st Century (2002) 1-13.

[19] W. F. Pickard, The history, present state, and future prospects of underground pumped hydro for massive energy storage, Proceedings of the IEEE 100 (2) (2012) 473-483.

[20] R. Bracke, G. Bussmann, Heat-Storage in Deep Hard Coal Mining Infrastructures, World Geothermal Congress 20152010 (2015) 1-8.

[21] M. Lutyński, An overview of potential benefits and limitations of Compressed Air Energy Storage in abandoned coal mines, IOP Conference Series: Materials Science and Engineering 268 (2017) 012006.

[22] P. Fraenkel, M. Wright, Apparatus and method for electrical energy storage (2013). URL patents.google.com/patent/GB2518125A/en

[23] P. Ribeiro, B. Johnson, M. Crow, A. Arsoy, Y. Liu, Energy storage systems for advanced power applications, Proceedings of the IEEE 89 (12) (2001) 1744-1756.

[24] O. Babacan, E. L. Ratnam, V. R. Disfani, J. Kleissl, Distributed energy storage system scheduling considering tariff structure, energy arbitrage and solar PV penetration, Applied Energy 205 (2017) 1384-1393.

[25] L. Johnston, F. Díaz-González, O. Gomis-Bellmunt, C. Corchero-García, M. Cruz-Zambrano, Methodology for the economic optimisation of energy storage systems for frequency support in wind power plants, Applied Energy 137 (2015) 660-669.

[26] Gravitricity Energy Storage System May Offer Lower Cost of Energy Storage than Batteries or Other Alternatives, Tech. rep., Storage Lab, accessed Jan. 92019 (2018). URL https://www.storage-lab.com

[27] N. Zhao, S. Member, N. Schofield, W. Niu, Energy Storage System for a Port Crane Hybrid Power-Train 2 (4) (2016) 480-492.

[28] N. Mitrovic, M. Petronijevic, V. Kostic, B. Jeftenic, Electrical Drives for Crane Application, in: Mechanical Engineering, InTech, 2012.

[29] W. G. Pariseau, J. C. Johnson, M. M. McDonald, M. E. Poad, Rock Mechanics Study of Shaft Stability and Pillar Mining, Homestake Mine, Lead, SD, Tech. rep., U.S. Department of the Interior, Bureau of Mines, accessed Jan. 92019 (1996).

URL https://www.cdc.gov/niosh/mining/works/coversheet1014.html

[30] C. M. Burt, X. Piao, F. Gaudi, B. Busch, N. F. Taufik, Electric Motor Efficiency Under Variable Frequencies and Loads, Journal of Irrigation and Drainage Engineering 134 (2) (2008) 129-136.

[31] ABB, HV induction motors, technical catalog for IEC motors EN 072016, BU Motors and Generators. URL abb.com/abblibrary/downloadcenter

[32] ArcelorMittal, High quality ropes for mining applications. URL http://ds.arcelormittal.com/wiresolutions

[33] G. Rebel, R. Verreet, I. Ridge, Lightweight ropes for lifting applications, OIPEEC Conference Proceedings (2006) 33-54.

[34] B. Lu, M. Stocks, A. Blakers, K. Anderson, Geographic information system algorithms to locate prospective sites for pumped hydro energy storage, Applied Energy 222 (2018) 300-312.

[35] Yantai Raffles' world-record gantry crane should see first lift this year, Offshore 68 (6) (2008) 102.

[36] A. Berrada, K. Loudiyi, I. Zorkani, System design and economic performance of gravity energy storage, Journal of Cleaner Production 156 (2017) 317-326. 